
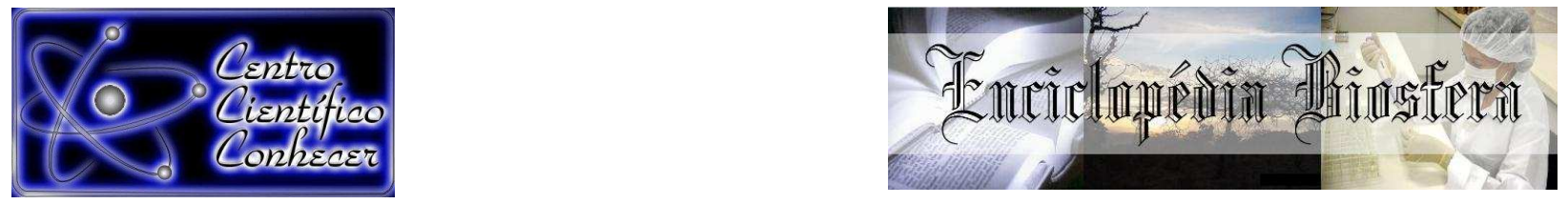

\title{
CARACTERIZAÇÃO TECNOLÓGICA DA MADEIRA DE Myracrodruon urundeuva EM DIFERENTES CLASSES DIAMÉTRICAS
}

\author{
José Benedito Guimarães Junior ${ }^{1}$, Jéssica Thaís Cangussu² ${ }^{2}$, Fernando Jesus \\ Nogara Lisboa ${ }^{3}$, Íngrid Luz Guimarães ${ }^{4}$ \\ ${ }^{1}$ Professor Doutor de Engenharia Florestal na Universidade Federal de Lavras - \\ Lavras - Minas Gerais - Brasil (jbguimaraesjr@hotmail.com) \\ ${ }^{2}$ Engenheira Florestal formada pela Universidade Federal de Goiás \\ ${ }^{3}$ Mestrando em Agronomia na Universidade Federal de Goiás \\ ${ }^{4}$ Mestranda em Agronomia na Universidade Federal de Goiás
}

Recebido em: 03/10/2016 - Aprovado em: 21/11/2016 - Publicado em: 05/12/2016 DOI: 10.18677/EnciBio_2016B_022

\begin{abstract}
RESUMO
O presente trabalho teve por objetivo determinar as características tecnológicas da madeira de Myracrodruon urundeuva, em diferentes classes diamétricas. Para isso, a proporção de cerne/alburno foi determinada e a densidade básica foi quantificada pela norma ABNT (11941:2003) e a retratibilidade pela norma ABNT (7190:1997). Os valores da porcentagem de cerne para as classes diamétricas variaram de 4,42 a $21,15 \%$, ao passo que para o alburno variaram de 78,85 a $95,56 \%$. A relação cerne/alburno não apresentou efeito das diferentes classes diamétricas. A porcentagem de cerne decresceu da base para o topo, enquanto a porcentagem de alburno aumentou ao longo da posição longitudinal. A relação cerne/alburno decresceu da base para o topo. Não houve diferença significativa da densidade básica entre as classes diamétrica. A densidade básica decresceu da base até a posição de $75 \%$ e, posteriormente, foi crescente até o topo. Para a retratibilidade linear, foram constatados menores valores para a classe diamétrica entre 25,9-32,9 $\mathrm{cm}$. Quanto ao coeficiente anisotrópico, o mesmo foi estatisticamente igual entre as classes diamétrica. A madeira de Myracrodruon urundeuva pode ser classificada como fator de anisotropia normal.
\end{abstract}

PALAVRAS-CHAVE: Cerne e alburno, Densidade básica, Retratibilidade.

\section{TECHNOLOGICAL CHARACTERIZATION OF WOOD Myracrodruon urundeuva IN DIFFERENT DIAMETER CLASSES}

\begin{abstract}
This study aimed to determine the technical characteristics of Myracrodruon urundeuva wood in different diameter classes. For this, it was determined the heartwood/sapwood proportion and the basic density was quantified by the ABNT (11941: 2003) and the shrinkage by the ABNT (7190: 1997). The values for the percentage of core diameter classes ranged from 4.42 to $21.15 \%$, while for the sapwood ranged from 78.85 to $95.56 \%$. The heart/sapwood relationship did not effect on the different diameter classes. The percentage of core decreased from bottom to top, while the percentage of sapwood increased along the longitudinal position. The core relationship/sapwood decreased from bottom to top. There was no significant difference in specific gravity between the diametric classes. The basic density
\end{abstract}


decreased from the base to the position of $75 \%$ and was subsequently rising to the top. For the linear shrinkage, were observed lower values for diameter class between 25.9 to $32.9 \mathrm{~cm}$. As for the anisotropic coefficient, it was statistically equal between the diametric classes. The Myracrodruon urundeuva wood can be classified as normal anisotropy factor.

KEYWORDS: Heartwood and sapwood, Basic density, Shrinkage.

\section{INTRODUÇÃO}

O Brasil é conhecido como um país tropical, que vem se destacando mundialmente devido à diversidade de flora. Em suas florestas, são encontradas diversas espécies com alto valor econômico, dentre elas podemos destacar a aroeira (Myracrodruon urundeuva Fr. All.), pertencente à família Anacardiaceae, e com distribuição geográfica principalmente no Bioma Cerrado, Mata Atlântica e Caatinga. A madeira dessa espécie é amplamente empregada pela sua excelente característica de durabilidade natural, sendo utilizada em construções civis, móveis torneados e piso. Além de seu valor madeireiro, oferece valor medicinal, paisagístico e forrageiro (CARVALHO et al., 2003).

Dado a variedade de fins tecnológicos de $M$. urundeuva, devido o pouco conhecimento acerca de sua madeira, é de suma seriedade estudos sobre a caracterização tecnológica. Segundo OLIVEIRA \& SILVA (2003), a madeira é um sistema complexo, tornando-se um material de extrema variabilidade. Sua estrutura e composição química, bem como suas propriedades físicas e mecânicas, variam significativamente entre espécies, entre árvores de uma mesma espécie e, mesmo, entre diferentes partes de uma mesma árvore. Logo, a caracterização é um passo importante na definição da utilização final do produto.

Dentre as características tecnológicas da madeira, destaca-se a densidade básica. Essa é indiscutivelmente um dos principais parâmetros de qualidade da madeira, pois além de ser facilmente determinado, apresenta influência na produtividade energética, na qualidade do produto final, nas propriedades térmicas, físicas (retratibilidade) e nas resistências mecânicas da madeira.

Para OLIVEIRA et al. (1990), a determinação da densidade básica não é suficiente para indicar com segurança uma correta utilização para a madeira. Assim, estudos das suas variações dimensionais são necessários. A retratibilidade pode ser definida como uma forma de variação dimensional da madeira quando há alteração no seu teor de umidade, resultando na movimentação de água abaixo do ponto de saturação das fibras (OLIVEIRA, 1998).

De acordo com OLIVEIRA \& SILVA (2003), devido ao comportamento anisotrópico, as mudanças dimensionais observadas na madeira são diferentes ao longo das três direções estruturais. Geralmente, a contração na direção tangencial é aproximadamente, duas vezes maior que na direção radial, enquanto no sentido longitudinal é, praticamente, desprezível. DURLO \& MARCHIORI (1992) afirmam que o mais importante índice para se avaliar a estabilidade dimensional da madeira é o coeficiente ou fator anisotrópico, definido pela relação entre as contrações tangencial e radial. Quanto maior essa relação, maior será a tendência ao fendilhamento e empenamento da madeira.

Do ponto de vista da anatomia da madeira, características macroscópicas, como a quantificação das porcentagens de cerne e alburno, são de extrema importância, pois maiores quantidades de cerne são desejáveis para a produção de móveis e para suas aplicações na construção civil (PEREIRA et al., 2013). Por outro lado, 
podem dificultar a secagem da madeira, uma vez que o cerne é bastante impermeável (GALVÃO et al., 1985).

É sabido que a madeira é um material de origem biológica, tornando-se um sistema anisotrópico, heterogêneo e complexo. Por ser de extrema variabilidade, suas propriedades físicas, anatômicas e mecânicas são fortemente influenciadas pela idade, qualidade de sítio e classe diamétrica. LIMA et al. (2011) afirmam que a classe diamétrica exerce influência sobre as propriedades anatômicas da madeira. Já SANTANA (2009) verificou que a classe diamétrica tem um efeito significativo nas propriedades físicas da madeira, que, para a densidade básica da madeira, os valores médios apresentaram, de forma geral, tendência de crescimento com 0 aumento do diâmetro da árvore. Portanto, há escassez de informações sobre o efeito da classe diamétrica nas propriedades da madeira, assim tornam-se necessários estudos a fim de ter uma maior concepção do comportamento dessas variáveis na qualidade do produto final.

Face ao exposto, objetivou-se determinar as características tecnológicas da madeira de Myracrodruon urundeuva em diferentes classes diamétricas e indicar alguns dos seus potenciais usos.

\section{MATERIAL E MÉTODOS}

Foram abatidas nove árvores de Myracrodruon urundeuva, provenientes de um fragmento de Floresta Estacional Decidual (IBGE, 2012), no município de Jataí,

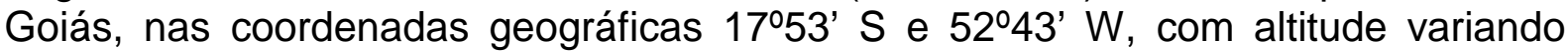
entre 617 e $641 \mathrm{~m}$, em área pertencente a Regional Jataí da Universidade Federal de Goiás. Os solos do fragmento são classificados como Latossolo Vermelho distrófico (EMBRAPA, 1999). O clima da região, de acordo com a classificação de Köppen, é do tipo Aw tropical de savana, mesotérmico, com chuva no verão e seca no inverno.

O levantamento dos indivíduos de aroeira foi realizado por meio de censo florestal, ou inventário a 100\%. Todos os indivíduos com cap (circunferência a 1,3 m do solo) $\geq 15,7 \mathrm{~cm}$ foram identificados, georreferenciados e mensurados. Foi mensurado um total de 1.807 indivíduos de aroeira, com diâmetro médio de $15,5 \mathrm{~cm}$ e desvio padrão de $\pm 7,0 \mathrm{~cm}$, os quais estão distribuídos em toda a área do fragmento (Figura 1).

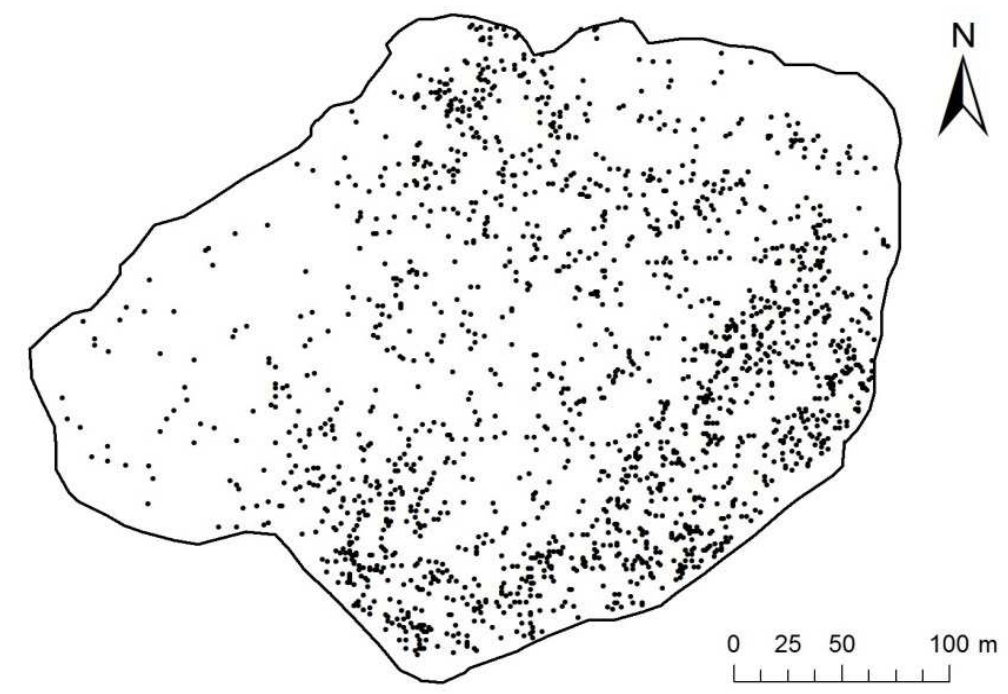


FIGURA 1. Distribuição dos indivíduos de Myracrodruon urundeuva com cap $\geq 15,7 \mathrm{~cm}$ no fragmento estudado, Jataí, GO (MATIAS, 2013).

Nessa área, foram avaliadas 3 classes diamétricas, conforme visualizado na Tabela 1.

TABELA 1: Números de árvores de M. urundeuva abatidas por classe diamétrica

\begin{tabular}{cc}
\hline Classe diamétrica $\mathbf{( c m )}$ & Números de árvores abatidas \\
\hline $5,0 \neg 12,0$ & 3 \\
$12,0 \neg 18,9$ & 3 \\
$25,9 \neg 32,9$ & 3 \\
\hline
\end{tabular}

Após a derrubada, as árvores foram seccionadas em diferentes alturas, sendo retirados discos com, aproximadamente, $3 \mathrm{~cm}$ de espessura a 0, 25, 50, 75 e $100 \%$ da altura comercial da árvore, além de um disco retirado na altura do peito - DAP (tomada de diâmetro a 1,30 $\mathrm{m}$ do solo).

Para a determinação da porcentagem de cerne e alburno, com uma régua foram feitas as medições do diâmetro total e do diâmetro do cerne. Para a determinação da porcentagem de cerne e alburno, utilizaram-se as equações 1 e 2 :

$C_{96}=\frac{D c^{2}}{D t^{2}} 100 \quad$ (equação 1)

$A_{96}=\left(\frac{D t^{2}-D c 2}{D t^{2}}\right) 100 \quad$ (equação 2)

em que:

$C_{0, \mathrm{c}}$ : porcentagem de cerne;

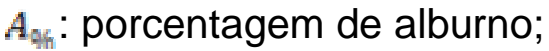

$D t$ : diâmetro total, em $\mathrm{cm}$; e

$D c$ : diâmetro de cerne, em $\mathrm{cm}$.

A relação cerne/alburno foi dada pela razão da porcentagem de cerne e alburno e para a determinação da densidade básica, utilizaram-se cunhas retiradas de diversas regiões longitudinais das árvores. Foi mensurado o volume saturado por meio do método da imersão, conforme a norma NBR 11941 (ABNT, 2003).

A retratibilidade da madeira foi determinada de acordo com norma NBR 7190 (ABNT, 1997). Nesse sentido, foram retirados corpos-de-prova devidamente orientados dos discos no DAP (Figura 2). Já o coeficiente de anisotropia foi determinado pela razão da retratibilidade tangencial e retratibilidade radial. 


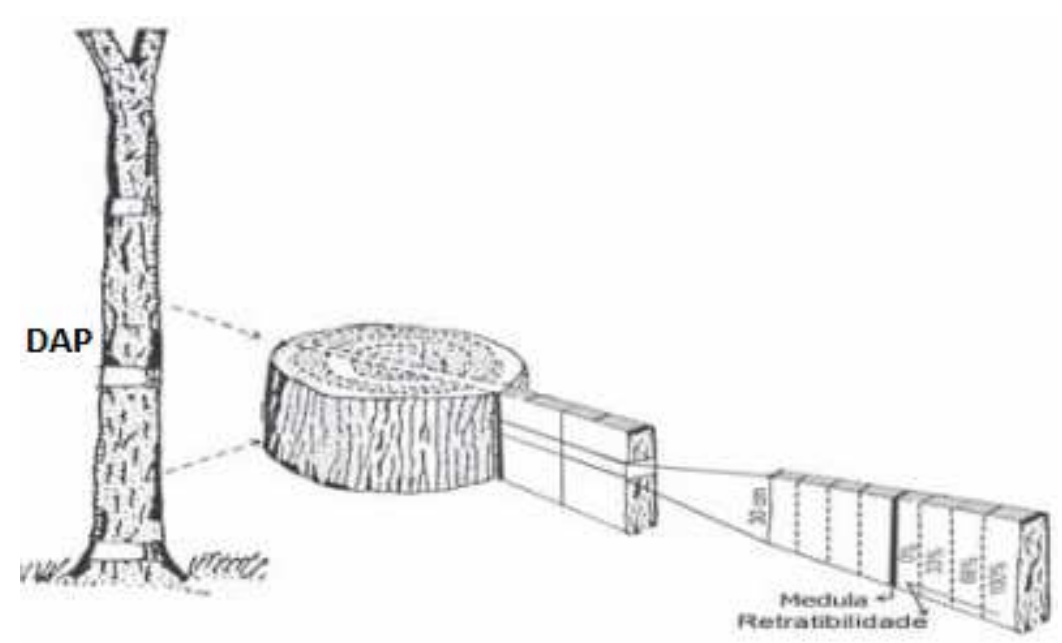

FIGURA 2. Retirada das amostras para ensaios da retratibilidade.

O delineamento utilizado foi o inteiramente casualizado com arranjo em fatorial, considerando a classe diamétrica como fator 1 e a posição longitudinal como fator 2 . Para a distinção de médias, quando necessário, utilizou-se o teste de Tukey a $5 \%$ de significância e regressão.

\section{RESULTADOS E DISCUSSÃO}

Não houve interação estatística significativa entre os fatores estudados (classe diamétrica; eixo longitudinal), sendo assim, as variáveis foram estudadas separadamente. A distribuição da porcentagem de cerne e alburno para madeira de aroeira está apresentada na Tabela 2.

TABELA 2: Valores de cerne, alburno, e relação cerne/alburno (C/A) para madeira de Myracrodruon urundeuva em diferentes classes diamétricas.

\begin{tabular}{cccc}
\hline $\begin{array}{c}\text { Classe diamétrica } \\
(\mathbf{c m})\end{array}$ & Cerne (\%) & Alburno (\%) & C/A \\
\hline $5,0 \neg 12,0$ & $4,42 \mathrm{~A}$ & $95,56 \mathrm{~B}$ & $0,35 \mathrm{~A}$ \\
$12,0 \neg 18,9$ & $6,67 \mathrm{~A}$ & $93,33 \mathrm{~B}$ & $0,10 \mathrm{~A}$ \\
$25,9 \neg 32,9$ & $21,15 \mathrm{~B}$ & $78,85 \mathrm{~A}$ & $0,32 \mathrm{~A}$ \\
\hline $\mathrm{CV}(\%)$ & 26,33 & 13,81 & 36,90 \\
\hline
\end{tabular}

$\mathrm{CV}=$ coeficiente de variação. Médias seguidas por uma mesma letra na coluna, não diferem estatisticamente entre si pelo teste de o Tukey ao nível de $5 \%$ de probabilidade.

Observa-se que a maior quantidade de cerne foi obtida na classe de diâmetro de $25,9 \neg 32,9 \mathrm{~cm}$, quando comparado com as classes de 5,0 $\neg 12,0$ e 12,0 $\neg 18,9 \mathrm{~cm}$. Comportamento contrário foi observado para a proporção de alburno. Esse resultado pode ser explicado devido ao maior diâmetro, uma vez que o aumento em diâmetro do fuste resulta em uma maior tendência de produção de cerne. Sobre a relação cerne/alburno, não houve diferenças significativas entre as classes diamétricas.

O estudo da proporção de cerne e alburno para o eixo longitudinal pode ser visualizado nas Figuras 2 e 3, respectivamente. 


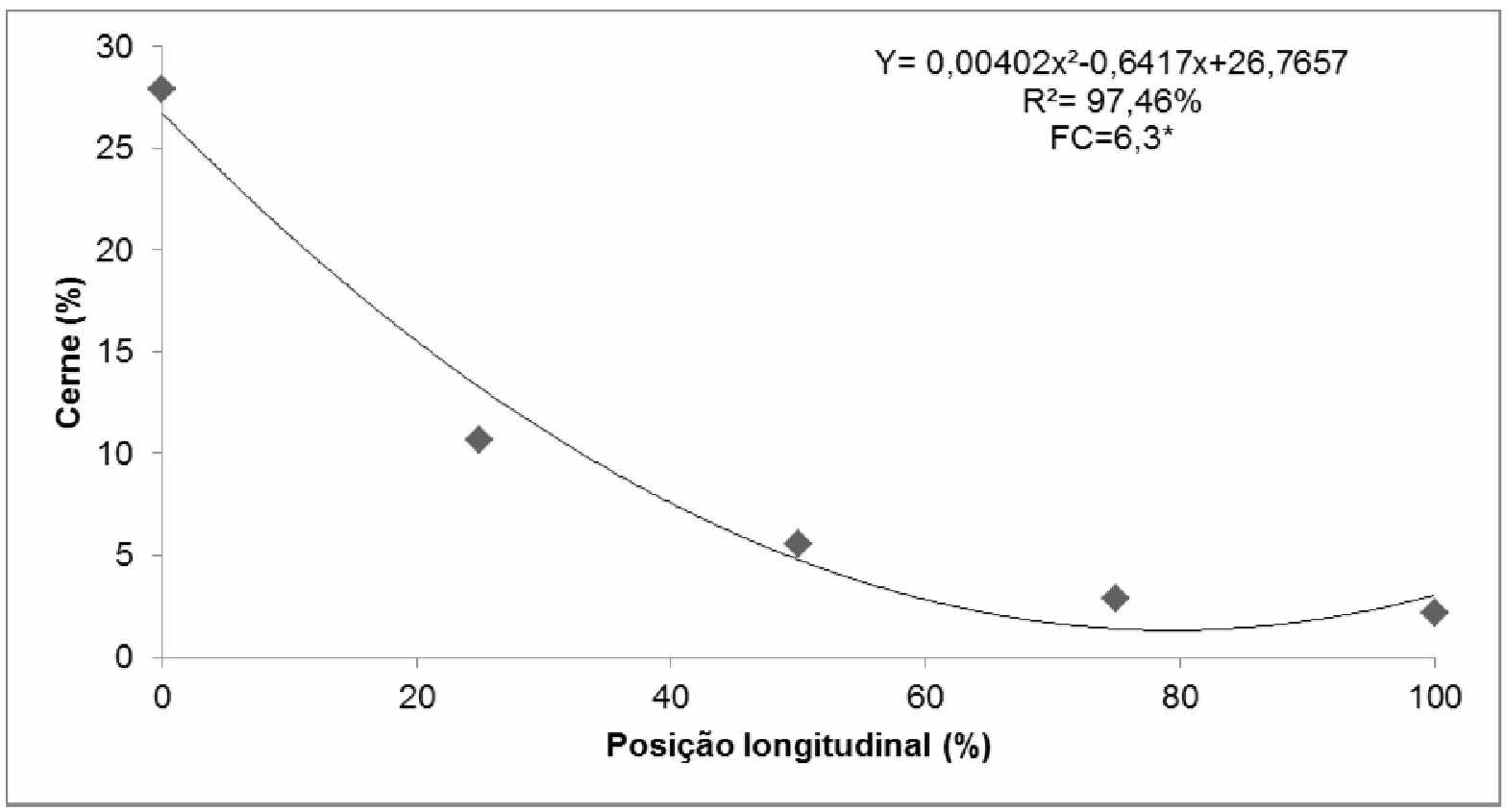

FIGURA 2: Porcentagem de cerne ao longo do eixo longitudinal do tronco.

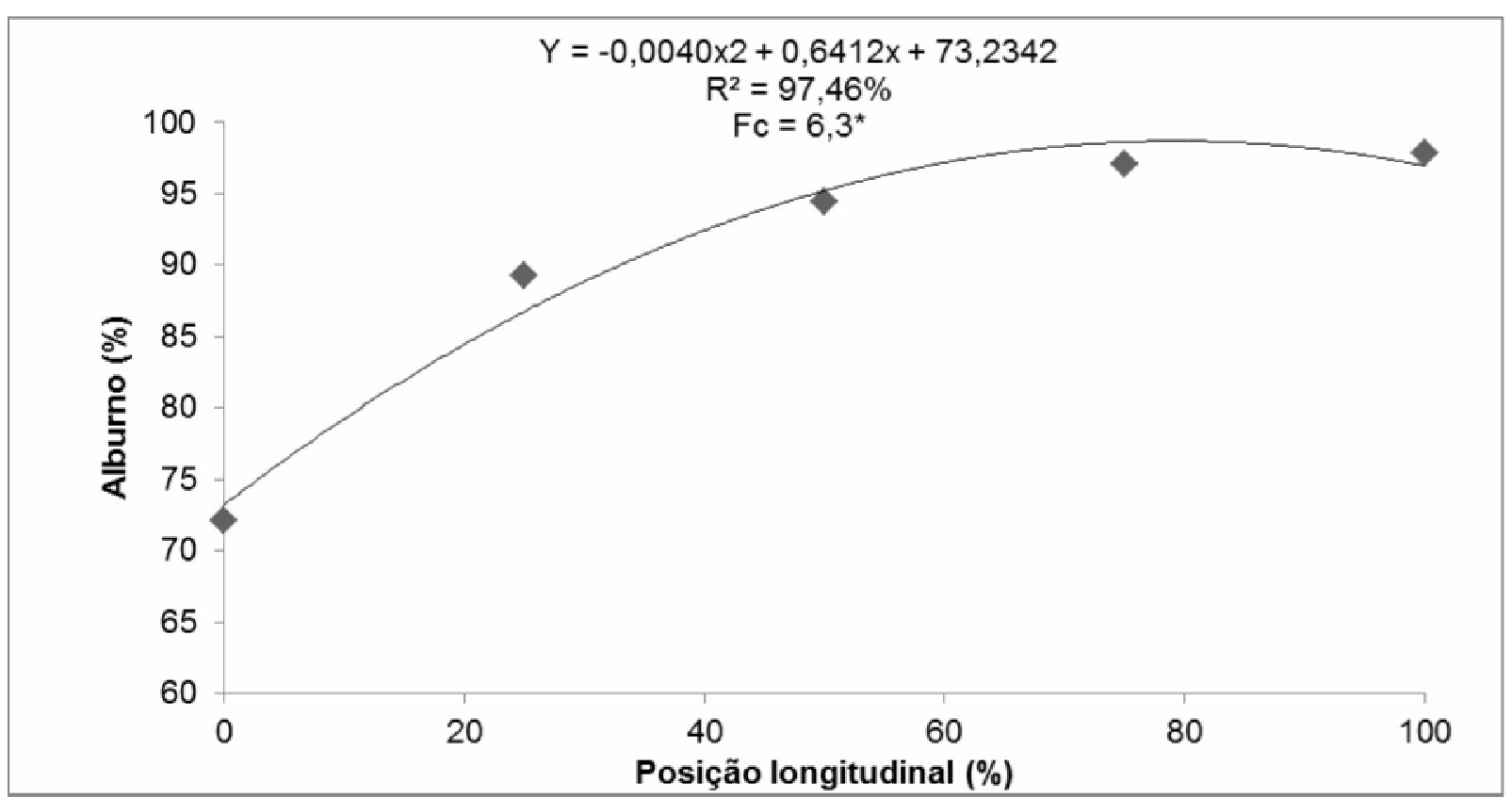

FIGURA 3: Porcentagem do alburno nas posições longitudinais do tronco.

$\mathrm{Na}$ Figura 2, nota-se decréscimo significativo do cerne no sentido longitudinal da árvore. Segundo PEREIRA et al. (2013), existe mais madeira jovem do que adulta nas posições mais altas e, como o desenvolvimento do cerne acompanha o avanço da idade do lenho, a proporção do mesmo é maior onde o lenho é mais velho, ou seja, a proporção de cerne diminui da base para o topo da árvore.

$\mathrm{Na}$ Figura 3, a proporção de alburno aumenta consideravelmente da base em direção ao topo do fuste. SILVA (2007) explica que esse comportamento da madeira se deve pelo o mesmo ser juvenil. Como não foram encontrados parâmetros na literatura para Myracrodruon urundeuva, cita-se o trabalho de GONÇALVES et al. (2010), que observaram a mesma tendência em sua pesquisa sobre caracterização 
físico-química da madeira de Mimosa caesalpiniaefolia, cuja porcentagem de cerne e alburno de $41,1 \%$ e $58,9 \%$, respectivamente.

A relação cerne/alburno ao longo do fuste para as madeiras de aroeira é apresentada na Figura 4.

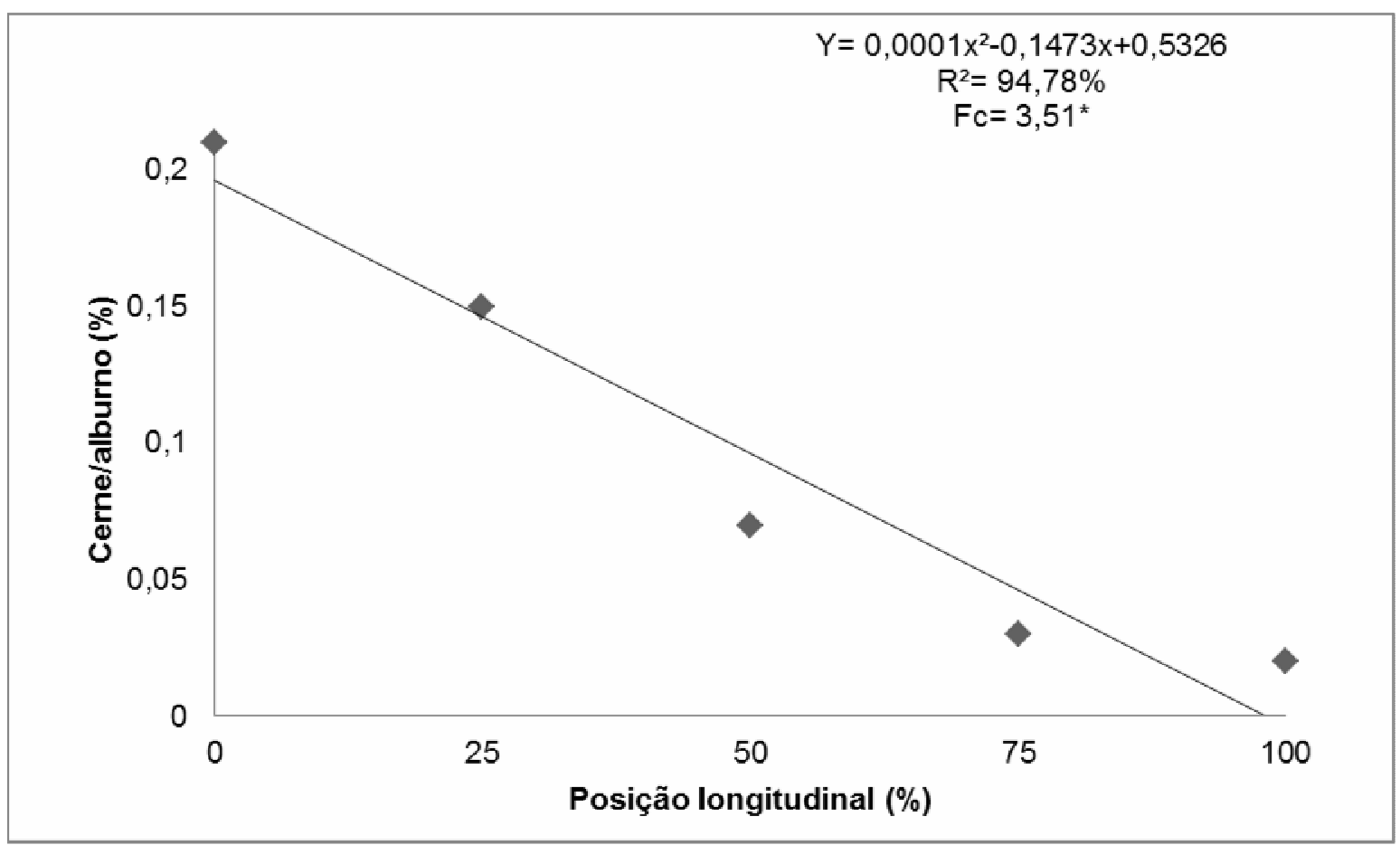

FIGURA 4: Relação cerne/alburno ao longo do eixo longitudinal do tronco.

Por meio da Figura 4, nota-se que a relação cerne/alburno decresce numa relação linear ao longo da posição longitudinal. Tal comportamento ocorre devido à proporção da madeira adulta ser maior na base, enquanto a madeira juvenil tem proporção maior no topo do tronco. De acordo com PEREIRA et al. (2013), essa relação cerne/alburno auxilia na definição do seu uso nos produtos finais, por exemplo, para a produção de carvão vegetal, papel e celulose, desdobro, painéis e outros. As densidades básicas médias obtidas para as madeiras de Myracrodruon urundeuva estão na Figura 5. 


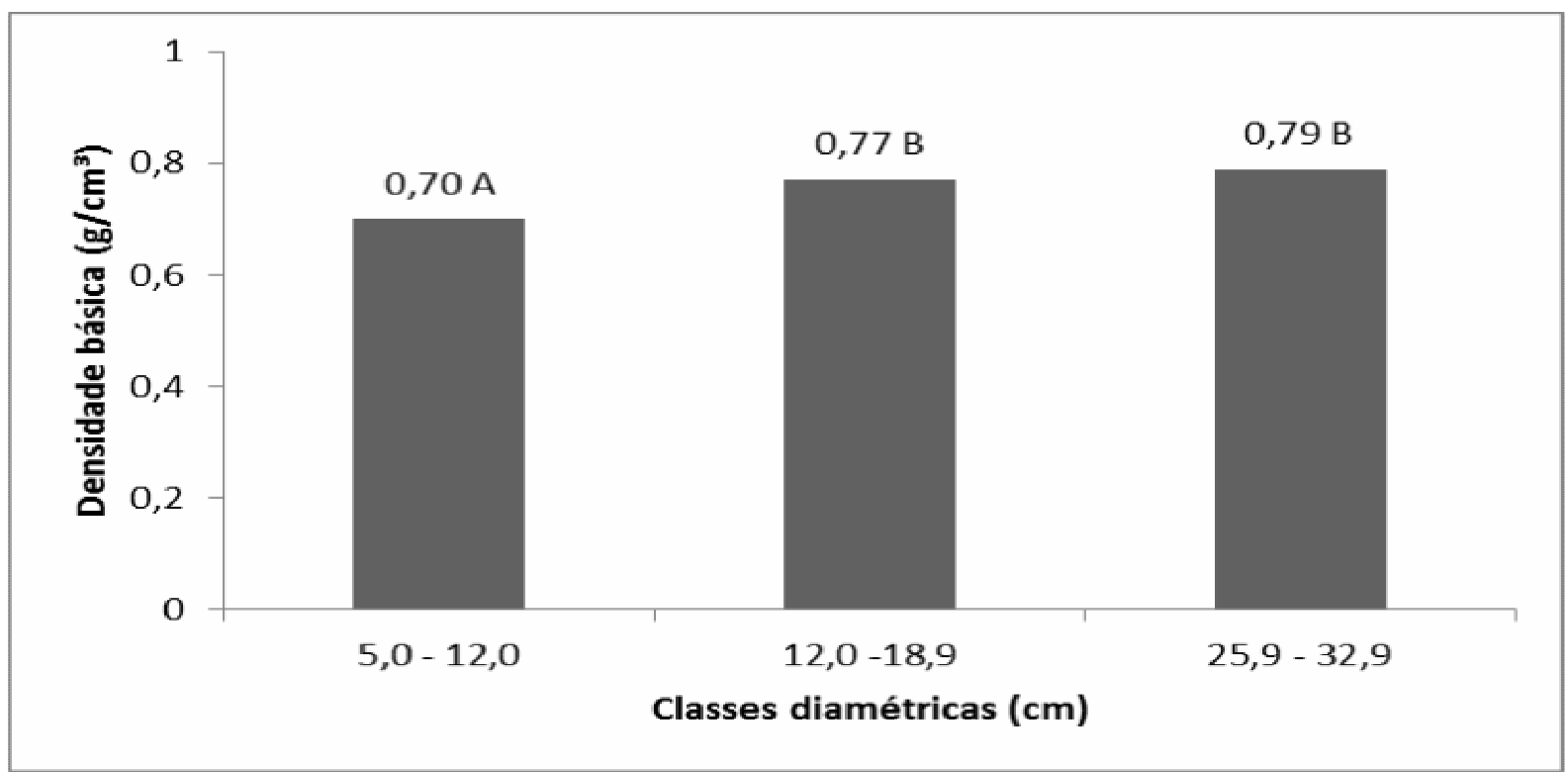

FIGURA 5. Densidade básica em diferentes classes diamétricas.

Analisando a Figura 5, observa-se que as duas classes de maiores diâmetros apresentaram maiores valores de densidade. Segundo classificação de densidades de MARQUES et al. (1997), pode-se afirmar que a espécie nas classes diamétricas de 12,0 a $18,9 \mathrm{~cm}$ e de 25,9 a $32,9 \mathrm{~cm}$ é constituída de madeira densa (densidade acima de $0,72 \mathrm{~g} / \mathrm{cm}^{3}$ ), enquanto que a classe de 5,0 a $12,0 \mathrm{~cm}$ é considerada de densidade básica média. FLORSHEIM \& TOMAZELLO FILHO (1998), em sua pesquisa sobre a variação da densidade básica da madeira de Myracrodruon urundeuva, tiveram valores de densidade básica que variaram de 0,63 a $0,77 \mathrm{~g} / \mathrm{cm}^{3}$ em três classes de diâmetro: $6-15 \mathrm{~cm}, 16-21 \mathrm{~cm}, 22-26 \mathrm{~cm}$. Sendo assim, os resultados obtidos estão de acordo com os encontrados na literatura. Os resultados da variação da densidade básica ao longo do fuste das madeiras de Myracrodruon urundeuva podem ser observados na Figura 6. 


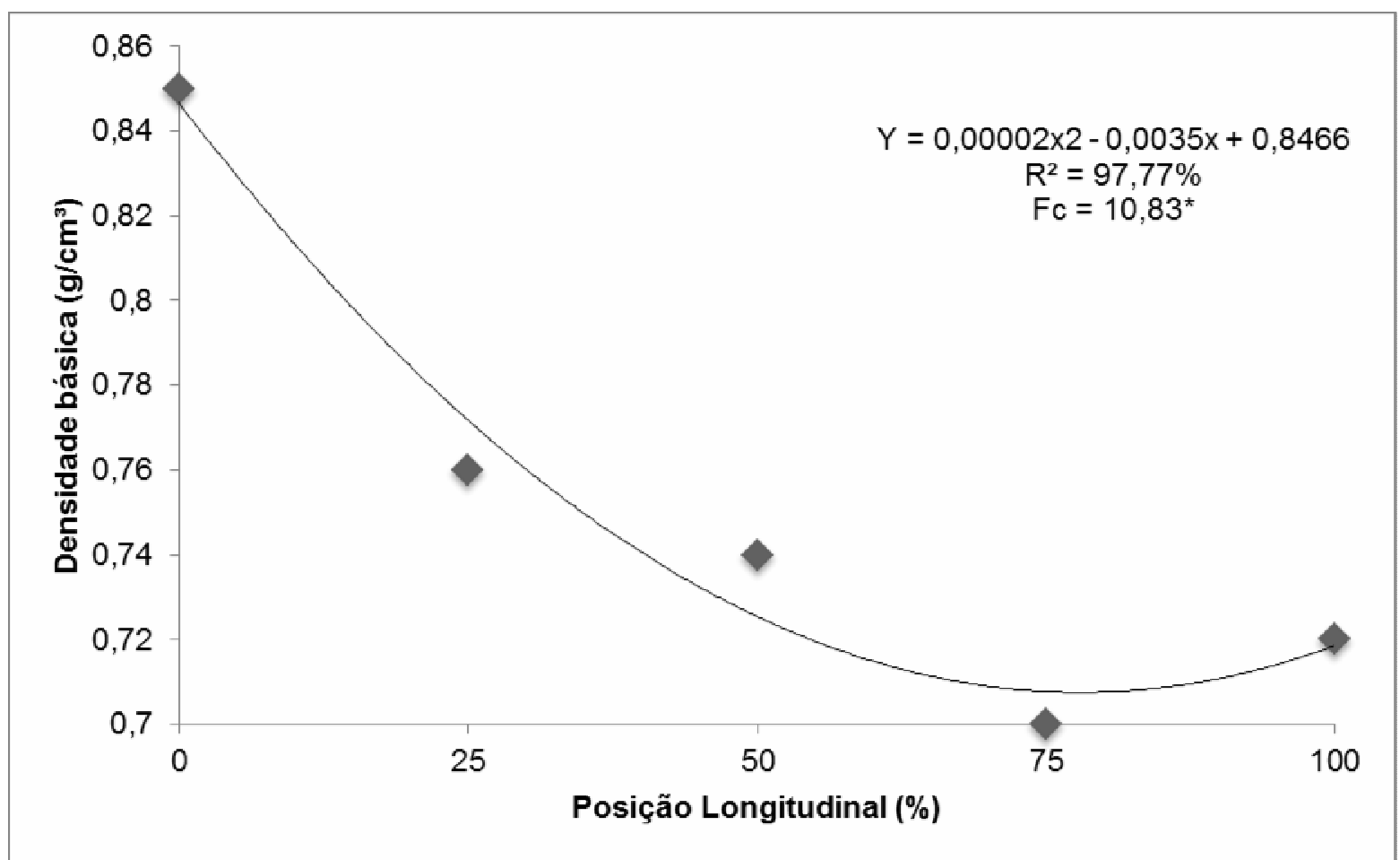

FIGURA 6: Variação da densidade básica no sentido longitudinal para as madeiras de Myracrodruon urundeuva em diferentes classes diamétricas.

Nota-se que o comportamento da densidade básica da madeira de aroeira ao longo do fuste é decrescente da base até a posição $75 \%$ e, por conseguinte, crescente até a posição $100 \%$ da altura comercial. FLORSHEIM \& TOMAZELLO FILHO (1998) não encontraram o mesmo comportamento para as madeiras de aroeiras. Em seu estudo, a densidade básica decresceu da base para o topo no sentido longitudinal. Já PALERMO et al. (2003) encontraram para madeira de Pinus elliottii decréscimo da densidade básica ao longo do tronco e acréscimo a partir da posição $75 \%$ da altura comercial. TRIANOSKI et al. (2013) obtiveram o mesmo comportamento em seu estudo sobre Pinus caribaea, Pinus chiapensis, Pinus maximinoi, Pinus oocarpa, Pinus taeda. PALERMO et al. (2003) explicaram que o aumento a $75 \%$ da altura comercial pode estar relacionado com a copa, pois na região de inserção dos ramos, ocorrem alterações na estrutura anatômica da madeira, provocando aumento da densidade. Os valores de retratibilidade linear, volumétrica e coeficiente anisotrópico, estão apresentados na Tabela 4.

TABELA 4: Valores de retratibilidade volumétrica e linear e coeficiente de anisotropia para madeira de Myracrodruon urundeuva.

\begin{tabular}{ccrcc}
\hline $\begin{array}{c}\text { Classe diamétrica } \\
(\mathrm{cm})\end{array}$ & \multicolumn{2}{c}{ Retratibilidade linear } \\
& \multicolumn{2}{c}{$(\%)$} & $\begin{array}{c}\text { Retratibilidade } \\
\text { Volumétrica } \\
(\%)\end{array}$ & $\begin{array}{c}\text { Coeficiente } \\
\text { anisotrópico } \\
(\%)\end{array}$ \\
\cline { 2 - 3 } & Radial & Tangencial & & \\
\hline $5,0 \neg 12,0$ & $6,45 \mathrm{~B}$ & $10,34 \mathrm{~B}$ & $16,30 \mathrm{~B}$ & $1,65 \mathrm{~A}$ \\
$12,0 \neg 18,9$ & $7,41 \mathrm{~B}$ & $11,16 \mathrm{~B}$ & $14,78 \mathrm{~B}$ & $1,50 \mathrm{~A}$ \\
$25,9 \neg 32,9$ & $3,99 \mathrm{~A}$ & $5,82 \mathrm{~A}$ & $9,46 \mathrm{~A}$ & $1,49 \mathrm{~A}$ \\
\hline $\mathbf{C V}(\%)$ & 18,14 & 18,94 & 35,10 & 24,85 \\
\hline
\end{tabular}

$\mathrm{CV}=$ coeficiente de variação. Médias seguidas por uma mesma letra na coluna, não diferem estatisticamente entre si pelo teste de Tukey ao nível de 5\% de significância. 
De acordo com a Tabela 4, os valores obtidos para a retratibilidade linear, no eixo radial e tangencial nas classes diamétricas $5,0 \neg 12,0$ e $12,0 \neg 18,9 \mathrm{~cm}$ foram estatisticamente iguais, enquanto a classe $25,9 \neg 32,9 \mathrm{~cm}$ foi superior as citadas anteriormente. Segundo TSOUMIS (1991), a magnitude da variação dimensional é normalmente maior na madeira de maior densidade, devido à maior quantidade de madeira por unidade de volume, fato que contrasta com os resultados obtidos neste trabalho. Tal comportamento pode ser explicado pela possível presença de teores de extrativos hidrofóbicos nas árvores de maiores diâmetros. Uma vez que esses compostos estão presentes nas paredes celulares, as contrações volumétricas tendem a não ser muito elevadas (OLIVEIRA et al., 2010). Além disso, MELO et al. (2010) afirmam que a madeira adulta tem maior estabilidade dimensional quando comparada com a juvenil. Os valores determinados neste estudo estão condizentes com OLIVEIRA et al. (2010) que em seu estudo encontraram valores de 5,7 a 7,1\% para o eixo radial e de 9,3 a 10,0\% para o eixo tangencial, respectivamente para Eucalyptus cloeziana, Corymbia citriodora.

Para a retratibilidade volumétrica da madeira de Myracrodruon urundeuva, observa-se que a classe de diâmetro 25,9 $\neg 32,9 \mathrm{~cm}$ apresentou menor média quando comparada com as classes de $5,0 \neg 12,0$ e 12,0 $\neg 18,9 \mathrm{~cm}$. FRANÇA (2014) encontrou tendência similar em sua pesquisa sobre caracterização físico-mecânica de duas espécies de mogno africano, em que o menor valor de retratibilidade volumétrica $(8,98 \%)$ foi constatado para Khaya senegalensis, com densidade básica de $0,59 \mathrm{~g} / \mathrm{cm}^{3}$, enquanto a espécie Khaya ivorensis teve valor de retratibilidade maior $(9,18 \%)$, com $0,49 \mathrm{~g} / \mathrm{cm}^{3}$ de densidade básica, e menor quando comparada com a outra espécie.

Observou-se que o coeficiente anisotrópico entre as classes diamétricas não diferiu estatisticamente. LOGSDON \& PENNA (2004) classificam a madeira como excelente aquelas que apresentam coeficiente anisotrópico até 1,5; normal para madeiras que tenha de 1,5 a 2,0; e ruim quando o coeficiente de anisotropia é maior que 2,0. Assim, por meio dos dados obtidos para a espécie em estudo, para o coeficiente de anisotropia obteve-se uma média de 1,55. Assim, pode-se deduzir que a madeira de Myracrodruon urundeuva tem fator anisotrópico normal.

NOCK et al. (1975) afirmam que o coeficiente de anisotropia pode ser usado na indicação da qualidade da madeira. Nessa perspectiva, a madeira de Myracrodruon urundeuva, em termo de utilização, é indicada para estantes, mesas e armários, sendo usos que permitam pequenos empenamentos.

\section{CONCLUSÃO}

As classes de maiores diâmetros apresentam maior proporção de cerne, sendo verificado um decréscimo da porcentagem de cerne da base em direção ao topo da árvore.

As classes diamétricas interferiram na densidade básica, sendo a madeira classificada como de alta densificação nas classes de 12,0 a $18,9 \mathrm{~cm}$ e de 25,9 a $32,9 \mathrm{~cm}$. Já a classe entre 5,0 a $12,0 \mathrm{~cm}$ foi considerada de mediana densidade. Foi verificado um decréscimo da densidade no sentido longitudinal da árvore.

A retratibilidade linear e volumétrica foi menor para as classes de maior diâmetro. Já quanto ao coeficiente anisotrópico, a espécie pode ser classificada como normal.

A espécie é indicada para estantes, mesas, armários, e usos que permitam pequenos empenamentos. 


\section{REFERÊNCIAS}

ABNT - ASSOCIAÇÃO BRASILEIRA DE NORMAS TÉCNICAS. NBR 11941: Madeira. Determinação. Rio de Janeiro, 2003. 6 p.

ABNT - ASSOCIAÇÃO BRASILEIRA DE NORMAS TÉCNICAS. NBR 7190: Projetos de estruturas e madeira. Rio de Janeiro, 1997. 107 p.

IBGE - INSTITUTO BRASILEIRO DE GEOGRAFIA E ESTATÍSTICA. Manual técnico da vegetação brasileira. Rio de Janeiro: IBGE, 2012. 275p.

CARVALHO, P. E. R. Aroeira verdadeira. EMBRAPA. 2003. Colombo. 16 p. (EMBRAPA-floresta. Curricular técnica, 82).

EMBRAPA - EMPRESA BRASILEIRA DE PESQUISA AGROPECUÁRIA. Sistema brasileiro de classificação de solos. Brasília: SPI/ CNPS, 1999. 412 p.

FRANÇA, T. S. F. A. Caracterização tecnológica das madeiras de duas espécies de Mogno Africano (Khaya ivorensis A. Chev. e Khaya senegalensis (Desr.) A. Juss.). 2014. 104 f. Dissertação (Mestrado em Ciências Florestais). Universidade Federal do Espírito Santo. Jerônimo monteiro. 2014.

FLORSHEIM, S. M. B.; TOMAZELLO FILHO, M. Variação da densidade básica da madeira de aroeira Myracrodruon urundeuva F.F. \& M.F. Allemão (ANACARDIACEAE). Revista Instituto Florestal, São Paulo, p. 53-61,1998.

GALVÃO , A. P.M. \& JANKOWSKY, I.P. Secagem racional da madeira. São Paulo: Nobel, 1985. 111p.

GONÇALVES, C. A.; LELIS, R. C. C.; ABREU, H. S. Caracterização físico-química da madeira de sabiá (Mimosa caesalpiniaefolia Benth.) Revista Caatinga, Mossoró, v. 23, n. 1, p. 54-62, 2010.

LIMA, I. L.; LONGUI. E. L.; GARCIA, R.; LUCA E. F.; JÚNIOR, F. G S.; FLORSHEIM, S. M. B. Propriedades da Madeira de Eucalyptus umbra R. T. Baker em Função do Diâmetro e da Posição Radial na Tora. Floresta e Ambiente, São Paulo; v.18, n. 3, p. 289-298, 2011. Disponível em: < http://dx.doi.org/10.4322/floram.2011.049>

LOGSDON, N. B.; PENNA, J. E. Análise comparativa entre os coeficientes de anisotropia dimensional da madeira, no inchamento e na retração. Agricultura Tropical, v. 8, n. 1, 2004.

MARQUES, M. H. B.; MELO, J. E. de; MARTINS, V. A. Madeiras da Amazônia: características e utilização. Brasília: Serviço Florestal Brasileiro. 141 p., 1997.

MATIAS, R. A. M. Quantificação de biomassa e estimativa de estoque de carbono de aroeira (Myracrodruon urundeuva All.). 2014. 13f. Monografia (Graduação em Engenharia Florestal) - Universidade Federal de Goiás, Jataí, 2014.

MELO R. R.; SATANGERLIN, D. M.; MENEZZI, C. H. S. D.; GATTO, D. A.; CALEGARI, L. Caracterização física e mecânica da madeira de Araucaria 
angustifólia (Bertol.) Kuntze. Revista Brasileira de Ciências Agrárias, Recife, v. 5, n. 1, p. 67-73, 2010. Disponível em: < http://dx.doi.org/10.5039/agraria.v5i1a515>.

NOCK, H. P: RICHTER, H. G.; BURGER, L. M. Tecnologia da madeira. Curitiba: Departamento de Engenharia e Tecnologia Rural, Universidade Federal do Paraná, 1975. $216 \mathrm{p}$.

OLIVEIRA, J. T. S.; TOMAZELLO FILHO, M.; FIEDLER, N. C. Avaliação da retratibilidade da madeira de sete espécies de Eucalyptus. Revista Árvore, Viçosa, v. 34, n. 5, p. 929-936, 2010. Disponível em: < http://dx.doi.org/10.1590/S0100$67622010000500018>$.

OLIVEIRA, J. T. S.; LUCIA, R.M.D.; VITAL, B.R. Estudos das propriedades físicas e tecnológicas da madeira da pindaíba (Xylopia lericea- It. Hill): densidade, umidade e secagem da madeira. Revista árvore, v. 14, n.1, p. 139-54. 1990.

OLIVEIRA, J.T.S.; SILVA, J. C. Variação radial da retratibilidade e densidade básica da madeira de Eucalyptus saligna Sm. Revista Árvore, Viçosa, v. 27, n. 3, p. 381385, 2003. Disponível em: <http://dx.doi.org/10.1590/S0100-67622003000300015>.

OLIVEIRA, J. T. S. Caracterização da madeira de eucalipto para a construção civil. 1998. 429f. Tese (Doutorado em Engenharia Civil) - Escola Politécnica, Universidade de São Paulo, São Paulo, 1998.

PALERMO, G. P.; LATORRACA, J. V. F.; REZENDE, M. A.; NASCIMENTO, A. M.; SEVERO, E, T. D.; ABREU, H. S. Análise da densidade da madeira de Pinus elliottii Engelm. Por meio de radiação gama de acordo com as direções estruturais (longitudinal e radial) e a idade de crescimento. Floresta e Ambiente, Botucatu, v. 10, n. 2, p. 47-57, 2003.

SANTANA, W. M. S. Crescimento, produção e propriedades da madeira de um clone Eucalyptus grandis e E. urophylla com enfoque energético. 2009. $91 \mathrm{f}$. Dissertação (Mestrado em Ciência e Tecnologia da madeira). Universidade Federal de Lavras. Lavras. 2009.

SILVA, M. R. Determinação da permeabilidade em madeiras brasileiras de florestas plantadas. 2007. 120 f. Dissertação (Mestrado em Engenharia de Materiais) - Universidade de São Paulo. São Carlos. 2007.

TRIANOSKI, R.; MATOS, J. L. M.; IWAKIRI, S.; PRATA, J. G. Variação longitudinal da densidade básica da madeira de espécies de Pinus tropicais. Floresta, Curitiba, v. 43 , n. 3 , p. 503-510, 2013. Disponível em < http://dx.doi.org/10.5380/rf.v43i3.28252>

TSOUMIS, G. Science and technology of wood: structure, properties and utilization. Van Nastrnd Reinold. New York: 1991. 494 p. 